\title{
The way ahead for polar science
}

\author{
The fourth International Polar Year is coming to an end. But the Arctic and Antarctic \\ must remain top scientific priorities.
}

N ext month's completion of the International Polar Year (IPY) is an occasion worth celebrating. Over two full Arctic and Antarctic field seasons, from March 2007 to March 2009, this global meta-project has successfully coordinated the efforts of some 50,000 scientists - including many from poorer nations, and from countries with a relatively new interest in polar research. It has also greatly advanced our still-sketchy understanding of physical, chemical and biological processes near the poles (see page 1072).

But the IPY also dramatized the polar regions' rapidly increasing connections to the rest of the globe. At the time of the last such exercise, the International Geophysical Year of 1957-58, the poles still seemed almost as remote as Mars. Today, they are feeling the effects of global climate change more intensely than anywhere else on Earth - and are fast becoming a new frontier for economic and political rivalries. Scientists and policy-makers should therefore think of this IPY not as a glorious endeavour that is now over and done with, but as a foundation on which to keep building.

The first priority is to ensure that the achievements of the IPY are exploited to the fullest. For example, the IPY programme has still not created a freely accessible archive for all the data and scientific findings harvested under its banner - information that will be in high demand from physical oceanographers, marine biologists, climate scientists and many others. Such an archive should be created as soon as possible, with funding coming from all the IPY nations relative to their economic strength. Nor has there yet been any systematic assessment of the IPY's scientific findings in a form that would be meaningful to decision-makers and the public at large. The International Arctic Science Committee and the Scientific Committee on Antarctic Research, the main organizations for polar science, are best placed to organize such an assessment. And Norway, which is a member of almost all the polar governance treaties and organizations, has promised to take the political lead in initiating the effort. It deserves the support of all the nations and organizations that participated in the IPY.

Looking to the future, meanwhile, polar stakeholders should vigorously pursue plans to create permanent observation networks at the poles. As the IPY itself underscored, for example, the rapidly warming climate creates an urgent need for ongoing ground observations of ice thickness and ice movement, as well as a new satellite infrastructure to monitor the cryosphere from space. The global economic downturn will obviously make it difficult for governments to fund such networks. But it is worth noting that at least some related projects will qualify for stimulus money - one of them being the Alaska Region Research Vessel, the new US flagship for polar research.

In parallel, the various polar stakeholders should pursue a sustainable, ecosystem-based management regime for both polar regions. New or improved international regulatory arrangements are needed in many areas, from fishing and shipping to pollution control and climate mitigation. And especially in the Arctic, which does not enjoy the international protections afforded the southern continent under "The first priority is to ensure that the achievements of the IPY are exploited to the fullest." the 50-year-old Antarctic Treaty, the rule-making process needs to encompass a hard, systematic look at economic and geopolitical governance. National directives on the Arctic issued by Russia, the United States, the European Union, Canada, Denmark and Norway suggest that future Arctic governance will be a delicate matter indeed. Add in the interest being shown by new players such as China and Brazil, and the need for concerted action is clear.

Finally, the new economic and political interest in the Arctic makes it all the more important that scientists keep alive the IPY's spirit of transnational cooperation. The poles have always drawn people with grand ambitions - not just scientists, but adventurers, military operatives and entrepreneurs of all stripes. And they are fast becoming more attractive, with all the potential for rivalry and discord that implies. Scientific collaborations will not stop that process. But they can keep alive important avenues of international communication, as they have in the past. And they can help nations remember that what happens at the poles is inseparable from what happens in the rest of the world.

\section{Europe's GM quandary}

\section{A political impasse over transgenic crops has left the European Commission with no good options.}

\footnotetext{
t seems like a lose-lose situation for Europe's environment commissioner, Stavros Dimas, whose thankless task it is to enforce the legislation that governs genetically modified (GM) crops.

Next week, the council of environment ministers from the 27 member states of the European Union (EU) will vote on whether
}

the insect-resistant maize MON801, the only GM crop approved for cultivation in Europe, should still be allowed. But a firm decision in favour or against will require what is known as a qualified majority, representing at least $62 \%$ of the EU population, and this degree of consensus seems unlikely given Europe's deep divisions over GM crops (see Nature 457, 946; 2009). So the decision is likely to get bumped up to the European Commission itself — which will be bound by its own rules to decide in favour, thereby unleashing political fireworks.

That the council should be involved at all in such a technical matter speaks volumes for how contentious this issue is. In 2004, 